\title{
Hume and Kant on Identity and Substance
}

\begin{abstract}
Mark Pickering
Published in Kant and the Scottish Enlightenment, edited by Elizabeth Robinson and Christopher Surprenant, 230-244. New York: Routledge, 2017.
\end{abstract}

Kant says that Hume woke him from his "dogmatic slumber” (P 4:260). Kant agrees with Hume that reason cannot give us the concept of cause and effect (P 4:310). Kant's argument for the apriority of the concept of and effect in his Second Analogy is frequently characterized as Kant's response to Hume. ${ }^{1}$ However, Hume's skepticism went much further than just the concept of cause and effect. As Kant recognized, reason also does not give us the concept of subsistence (P 4:310). Few scholars ${ }^{2}$ have asked whether Hume's skepticism about the concepts of identity and substance is adequately answered by Kant's argument in the First Analogy (CPR A182189/B224-232). In this paper I will argue that since Kant begs two questions against Hume, the argument of the First Analogy would be unacceptable to Hume.

The question of whether or not Hume's skepticism about the concepts of identity and substance is an interesting one because Hume and Kant both agree with regard to various claims they make when attempting to establish that we know or do not know that there is substance. Both philosophers affirm that we perceive a succession of impressions or appearances ( $\mathrm{T}$ 1.2.3.6 SBN 34; CPR A182/B225) and that this succession of impressions or appearances is distinct from the states of objects (T 1.4.2.14 SBN 193; CPR A182/B225). ${ }^{3}$ Further, both affirm that time itself cannot be perceived (T 1.2.3.7 SBN 35; CPR B225, A186/B226). Yet the two philosophers reached contrary conclusions. Hume's conclusion in the Treatise is that neither the senses nor reason give us adequate reason to believe in persisting objects (T 1.4.2.46 SBN 211). Kant's 
conclusion in the First Analogy is that we have experience of persisting, external objects (CPR A188/B231). How is this possible?

These disagreements stem from two more fundamental disagreements. The first regards the nature of experience. While Kant uses the term to denote a "systematic unity of perceptions" (CPR A183/B226), Hume gives no explicit account of 'experience' as Kant uses the term. Hume uses 'experience' to denote the daily consciousness of perceptions that we have (T 1.4.2.42 SBN 208; EHU 153). Since Kant's argument presupposes a thick concept of experience that Hume does not, Hume would never have accepted Kant's argument.

The second disagreement regards the nature of time. While Kant holds that time is an a priori form of sensible intuition (CPR A34/B50), Hume holds time to be derived from the succession of our impressions (T 1.2.3.6 SBN 34). Since Kant's argument presupposes that time cannot be empirically derived, Hume would have rejected Kant's argument.

I will first outline Hume's argument in the Treatise that we do not have the idea of identity or the idea of substance. Second, I will consider Kantian objections and Humean responses. Third, I will outline Kant's argument in the First Analogy that there must be substance. Fourth, I will consider Humean rejoinders to Kant's argument.

\section{Hume's Argument in the Treatise}

Hume argues that having a succession of impressions does not entitle us to the idea of identity or the idea of substance. In order to understand his arguments, it is necessary to understand the fundamentals of Hume's concept empiricism and his theory of perception. 
According to Hume, all true statements are true in virtue of either relations of ideas (a priori) or matters of fact (a posteriori) (EHU 20). Additionally, Hume holds that all ideas have their origin and their justification in impressions (T 1.1.1.1 SBN 1; EHU 13). Hume argues that the ideas of identity and substance are not ideas that come from the senses.

Hume argues that the idea of identity must come from either a single object or multiple objects. This is because any idea can only be justified by being derived from either one impression or a series of impressions. Neither can justify the idea of identity. Hume says, "The view of any one object is not sufficient to convey the idea of identity" (T 1.4.2.26 SBN 200). It is meaningless to say that a thing is identical with itself. Then Hume says, "On the other hand, a multiplicity of objects can never convey this idea, however resembling they may be suppos'd" ( $T$ 1.4.2.27 SBN 200). If we are talking about a multiplicity of objects, then they are different and not the same. "The mind always pronounces the one not to be the other," because, if it did not, then we would not be perceiving multiple objects in the first place (T 1.4.2.27 SBN 200). Since there are no other alternatives, we cannot get the idea of identity from the senses (T 1.4.2.28 SBN 200).

The supposed idea of identity refers to a multitude of non-identical impressions that justify concluding that an object has changed over time. Thus, the object at one time would, in some sense, be identical with an earlier object (T 1.4.2.29-30 SBN 200-201). Objects do seem to endure through time (T 1.4.2.31 SBN 201). This is due however not to the impressions that we have but rather to us taking similar ideas to be of an identical thing. Hume says the following about similar ideas that we take to be one: "The mind readily passes from one to the other, and perceives not the change without a strict attention, of which, generally speaking, 'tis wholly incapable" (T 1.4.2.32 SBN 202). It is the imagination which produces the unchanging object: 
A succession of related objects places the mind in this disposition, and is consider'd with the same smooth and uninterrupted progress of the imagination, as attends the view of the same invariable object. ... The passage betwixt related ideas is, therefore, so smooth and easy, that it produces little alteration on the mind, and seems like the continuation of the same action...'tis for this reason we attribute sameness to every succession of related objects. The thought slides along the succession with equal facility, as if it consider'd only one object; and therefore confounds succession with identity (T 1.4.2.34 SBN 203, emphasis added).

It is the "smooth and uninterrupted progress of the imagination" which misleads us into thinking that a "succession of ideas" is regarding one object (T 1.4.2.29 SBN 200). Hume says that "the constancy of our perceptions makes us ascribe to them a perfect numerical identity" (T 1.4.2.31 SBN 201) and that the constancy of our perceptions makes us "mistake one idea for another" (T 1.4.2.32 SBN 202). Hume summarizes his argument in the following passage:

'Tis a false opinion that any of our objects, or perceptions, are identically the same after an interruption; and consequently the opinion of their identity can never arise from reason, but must arise from the imagination. The imagination is seduc'd into such an opinion only by means of the resemblance of certain perceptions...the fiction of a continu'd existence; since that fiction, as well as the identity, is really false, as is acknowledg'd by all philosophers... (T 1.4.2.43 SBN 209). 
Another mistake is taking one action of the mind (as opposed to an idea) as being identical to another action of the mind when it is not identical. We mistake the action of the mind in perceiving a succession of objects that resemble one another with the action of the mind in perceiving a single object (T 1.4.2.35 SBN 204, n39). As Hume says, “An easy transition or passage of the imagination, along the ideas of these different and interrupted perceptions, is almost the same disposition of mind with that in which we consider one constant and uninterrupted perception. 'Tis therefore very natural for us to mistake the one [disposition of the mind] for the other [disposition of the mind]" (T 1.4.2.35 SBN 204, emphasis added).

Talk of acts of perceiving as resembling one another on top of talk of things being perceived resembling each other seems redundant. There can be no ideas without acts of perceiving. What matters is that impressions resemble one another, not that acts of perceiving resemble one another. Cannot acts of perceiving resemble one another even when different impressions are the content or object of the acts of perceiving? Hume has no answer. It appears to be a distinction without a difference. Perhaps Hume drew the distinction in order to emphasize that his focus was not so much on the content of mental acts as the mental acts themselves. Yet he indicates that either would have done for his fundamental purpose (T 1.4.2.35 SBN 204, n39).

In addition to denying that we have the idea of identity, Hume denies that we have the idea of substance. He considers the following definition of substance: "Something which may exist by itself" (T 1.4.5.5 SBN 233, emphasis removed). He then argues that if we accept this definition of substance, all of our perceptions are substances (T 1.4.5.5 SBN 233). Since this is clearly an absurd result, he rejects the definition. 
Hume argues that we cannot perceive a substance because an impression cannot resemble a substance. "For how can an impression represent a substance, otherwise than by resembling it? And how can an impression resemble a substance, since, according to this philosophy, it is not a substance, and has none of the peculiar qualities or characteristics of a substance?" (T 1.4.5.6 SBN 234). While these are phrased as questions, the following argument makes it clear how Hume would answer those two questions:

1. We have no perfect idea of anything but of a perception.

2. A substance is entirely different from a perception.

3. We have, therefore, no idea of a substance (T 1.4.5.6 SBN 234).

Therefore, our idea of substance does not come from sense.

If our belief in substance does not come from our impressions, then it must come from somewhere else. Hume argues that it comes from the imagination. We remember perceptions that resemble each other despite their being interrupted. This resemblance makes us identify them with each other by positing a continuing existence of a substance (T 1.4.2.42 SBN 208). As Hume says, "We have a propensity to feign the continu'd existence of all sensible objects; and as this propensity arises from some lively impressions of the memory, it bestows a vivacity on that fiction; or in other words, makes us believe the continu'd existence of body" (T 1.4.2.42 SBN 208). It is our memory and our imagination that are the source of our belief in substance. In other words, we have no idea of substance.

II. Kantian Objections and Humean Responses 
Though Kant does not respond directly to Hume's argument, we can see from some of Kant's related arguments how Kant could respond.

Kant would object that we cannot be aware of a mere succession of intuitions. This is because we cannot be aware of any intuitions without consciousness (CPR B131-132). ${ }^{4}$ Further, Kant would argue that we cannot have consciousness without synthesizing intuitions (CPR B133). We cannot synthesize intuitions without concepts (CPR B751). We can only synthesize intuitions under the concept of an object (CPR B137), which entails synthesizing intuitions under twelve particular concepts (CPR A80/B106). In other words, Kant would argue that we could not even be aware of a series of intuitions unless they referred to an object. ${ }^{5}$

Kant makes another argument against the possibility of our perceiving mere intuitions. Kant argues that representations count as mine only if the thought "I think" can accompany them (CPR B131). If that thought cannot accompany a representation, it means that something has been represented that cannot be thought. This would mean either that the representation is impossible for anyone or that the representation is impossible for me (CPR B131-132). Otherwise, Kant says, "I would have a self that was as many-sided as I have representations" (CPR B134). Kant seems to be saying that if the thought "I think" could not accompany my representations, I could not make a distinction between myself and my representations. Then I would have no reason to believe that I am different from my representations. ${ }^{6}$

Kant argues that without synthesis according to a priori concepts, a crowd of intuitions would fill our souls, we would have no cognition of objects, and we would not be able to arrive at universal and necessary laws (CPR A111). Further, we would have intuition without thought, which would be "for us as good as nothing at all" (CPR A111) and "less than a dream" (CPR 
A112). ${ }^{7}$ Kant says, "All representations have a necessary relation to a possible empirical consciousness: because if they did not have this, it would be completely impossible for us to be conscious of them" (CPR A117, note). For this reason, "the synthetic proposition that all different empirical consciousness must be combined in a single self-consciousness is simply the first and synthetic fundamental proposition of our thinking in general" (CPR A117, note).

For these reasons, Kant would object that a mere succession of intuitions would quite simply not be possible for us.

Three responses are open to Hume. First, Hume could respond that all impressions of which we are conscious must only apparently be of an object. This view would be based on introspective psychology: one cannot think of any impressions that are not apparently of an object. For Hume, our impressions of objects are only illusory. We actually have no impressions of objects, but only impressions that we mistakenly take to be of objects. However, while Hume says that we have impressions which we mistake for objects, Hume does not say that all impressions of which we are aware are necessarily those of objects. And it is obvious that some of our impressions are not even apparently of objects. Perhaps I feel a tingling sensation that does not apparently refer to any object.

A better response from Hume would be that Kant is begging a variety of questions in the transcendental deduction of the categories. For example, Hume could deny that consciousness requires synthesis. Hume says throughout the Treatise that we are conscious of this or not conscious of that, but he never says what consciousness is. ${ }^{8}$ But it seems likely that Hume would say that we passively receive impressions without needing to perform an act of synthesis. Why do we have to pick them out and stick them together in order to be aware of them? However, Hume does hold that the mind is a collection of perceptions that have certain relations to one 
another. "What we call a mind, is nothing but a heap or collection of different perceptions, united together by certain relations, and suppos'd, tho' falsly, to be endow'd with a perfect simplicity and identity" ( $\mathrm{T}$ 1.4.2.39 SBN 207). And he describes these relations as being the result of attractive forces between ideas analogous to gravity (T 1.1.4.1 SBN 10). These relations are the result of synthesis, but the synthesis Hume has in mind is mere association and a matter of descriptive psychology. ${ }^{9}$ The synthesis Kant has in mind is not a matter of mere association or descriptive psychology. Instead, the Kant argues that synthesis of a certain kind is a condition of the possibility of cognition in general, be it of humans or of non-humans (CPR Bxv-xx) ${ }^{10}$ So Hume should object not to the claim that synthesis is required for consciousness but rather to the claim that synthesis under particular concepts is required for consciousness.

It seems likely that Hume would have held that consciousness need be nothing other than a succession of impressions that bear certain relations to each other such as contiguity. This objection may be phrased in another way: we have no reason to believe that we have experience of the kind that Kant says we have.

Third, Hume could argue that Kant's argument against him is too strong. If intuitions without consciousness are nothing to us and are less than a dream, then it seems that we should not have illusions, hallucinations, or dreams. ${ }^{11}$ Clearly we do have these pseudo-experiences, so they are not nothing to us. A dream cannot be less than a dream. So Hume could argue that Kant must be wrong in saying that intuitions without consciousness are nothing to us or less than a dream.

As we saw in the previous section, Hume argued that experience could never justify belief in an object's existence in the first place. For Kant, experience entails making judgments about objects that include judgements as to the temporal states of that object as well as its 
relation in time to other objects. He takes the two to be inseparable for the reasons Kant gives in his argument in the First Analogy.

\section{Kant's Argument in the First Analogy}

In the transcendental deduction, Kant argued that experience is not possible without the categories (CPR A93/B126). One of those categories is substance (CPR A80/B106). However, Kant does not argue there that any particular category is necessary for experience. Kant argues in three places that there must be substance: in the First Analogy (CPR A182-189/B224-232), in the Refutation of Idealism (CPR B274-279), and in the General Remark on the System of Principles

(CPR B288-294). ${ }^{12}$ I will focus on the argument of the First Analogy, since its premises are the most similar to views held by Hume. In the following section, I will consider objections on Hume's behalf that the argument is unsound.

I will consider Kant's argument for the conclusion that substance is required for time determination (CPR A182-184/B224-227). I will not consider Kant's argument that the quantity of substance cannot increase or decrease (CPR A185-189/B228-232). Kant's argument is as follows:

1. All appearances are in a single, unchanging, unified time (CPR B224-225). ${ }^{13}$

2. We perceive a succession of appearances (CPR A182/B225).

3. This succession of appearances is distinct from the states of objects (CPR A182/B225). ${ }^{14}$

Therefore, 
4. The appearances themselves do not allow us to make determinations regarding the successive or coexistent states of objects unless something remains or endures of which all change and coexistence is a determination (CPR A182/B225-226).

Therefore,

5. Only in the enduring thing [das Beharrliche] are therefore time relations possible; that is, the enduring thing is the substratum of the empirical representation of time itself (CPR B225, A182-183/B226). ${ }^{15}$

Therefore,

6. The enduring thing in all appearances is substance (CPR A183-184/B227).

I will argue that Kant's argument is both invalid and unsound. However, not all criticisms leveled against it are fair. For example, while (1) is sometimes phrased in terms of the permanence of time, it is plain that Kant rejects the notion of time itself having duration. That would require time being nested within another time (CPR A183/B226; A188-189/B231-232). ${ }^{16}$ Therefore, Guyer's objection that it is incoherent to refer to the permanence of time is misplaced. $^{17}$

Graham Bird interprets (1-3) as talking about the succession of everyday experience, not of subjective appearances. ${ }^{18}$ However, Bird is mistaken. The text is perfectly clear on this matter. Kant says "Our apprehension of the manifold of appearance is always successive, and it is therefore always changing. We can therefore never determine through it alone whether this manifold, as object of experience, is simultaneous or follows another [manifold] if there is not 
something that underlies them..." (CPR A182/B225, emphasis added). Here Kant refers to our apprehension of a manifold of appearance, which is necessary but not sufficient for experience. Kant says that we cannot determine whether the manifolds we perceive are simultaneous or successive unless we posit something that underlies them.

The main problem with Kant's argument is that (4) does not follow from (1-3) and (5) does not follow from (1-4). For all Kant has says in (1-3), it still might be the case that appearances allow us to make time determinations without something enduring. This is precisely what empiricists like Hume have in mind when they say we infer time from the succession of our impressions (T 1.2.3.6 SBN 35).

It is remarkable that many Kant commentators are not critical of Kant's inferring (4) and (5). ${ }^{19}$ Dryer and Melnik make the leap from (1-3) to (4) without blinking. ${ }^{20}$ Allison does not describe why (4) follows from (1-3) or how (5) follows from (1-4). Allison suggests that he did not think they followed when he says that the object "must somehow embody the unchangeableness or persistence that has already been attributed to time itself." ${ }^{21}$ Guyer does not attempt to show how (4) or (5) follow from the preceding premises. ${ }^{22}$

At first glance, one cannot tell where (4) comes from. Kant does not argue for it, but apparently plucks it out of thin air. What premises must be added in order for (4) to follow from (1-3)? I suggest adding the following premises:

(a) We perform time determination

(b) We can perform time determination only by either

(i) perceiving time determinations in the appearances themselves

or 
(ii) inferring them based on the states of an object distinct from our appearances.

(c) We do not perceive time determinations in the appearances themselves.

There is good textual evidence for ascribing assumption (a) to Kant. Kant makes clear throughout the Critique that he begins with the assumption that we have experience (B1). ${ }^{23}$ Experience entails time determination (CPR A183/B226). Therefore, we perform time determination. Assumptions (b) and (c) are necessary for constructing a valid argument for (4) from (1-3) and (a). I impute (b) and (c) to Kant out of charity. We cannot infer (c) from Kant's statement that "Time cannot be perceived in itself" (CPR B225, A186/B226) because perceiving time itself is not self-evidently the same thing as making time determinations. Kant's assuming (a), (b), and (c) explains why Kant would conclude (4) from (1-3), since (4) follows from (1-3) in conjunction with (a-c).

(5) does not follow from (1-4). Just because perception of an object is required in order to perform time determinations does not mean that there is such an object or that we perceive it. But if we assume that we do perform time determinations and that we do so by inferring them from the states of an object (as (a-c) say), then (5) follows.

While I hope to have shown that Kant's argument is invalid, Bennett's criticism that the argument is "unintelligible" goes too far. ${ }^{24}$ It is easy enough to make sense of it if we add premises (a-c).

But validity is of course not enough to make an argument persuasive. How plausible are these premises? Guyer objects that (5) is contradicted by a statement elsewhere in the Critique. ${ }^{25}$ He objects that that Kant distinguishes between the enduringness of a representation and the 
enduringness of an object in the B Preface (CPR Bxli, note) ${ }^{26}$ But even if no representation is enduring, we may still get representations of enduringness by connecting these fleeting representations. Far from showing that Kant's statement contradicts what Kant says elsewhere, Kant is entirely consistent.

(c) begs the question of whether we infer time from the succession of appearances. Hume's view that we perform time determination by perceiving the succession in impressions themselves should not be ruled out without giving a reason for doing so. Kant denies the empiricist view of time in the Transcendental Aesthetic, but his argument is question-begging. Kant states that "Time is...not an empirical concept that is derived from an experience. This is because simultaneity or succession would not come in perception if the representation of time did not underlie it a priori" (CPR A30/B46). ${ }^{27}$ Kant is saying that time cannot be derived from experience if time is not derived from experience. Kant does not even bother to attempt to refute the empiricist view, but instead presupposes that it is false. ${ }^{28}$ As Lorne Falkenstein says, "The Metaphysical and Transcendental Expositions never address the possibility that space and time might exist independently in their own right or be determinations or relations of independently existing entities. ${ }^{29}$ In the Transcendental Aesthetic, Kant is only interested in expositing his view that space and time are nothing but forms of intuition. He is not interested in ruling out alternative views of space and time. ${ }^{30}$

This concludes my discussion of Kant's argument in the First Analogy. I have argued that it is invalid but that it is not difficult to add premises to make it valid. However, the added premise (c) begs the question of the apriority of time.

\section{Humean Rejoinders}


A Humean would not find Kant's argument in the First Analogy to be persuasive because Hume would not accept premises (1), (4), (5), or assumption (c). I will give textual evidence for my assertion below. First I will give an overview of Hume's account of time. This is necessary to show why Hume would have rejected certain of Kant's premises in that it serves as a counterexample to Kant's claims.

For Hume, time is an abstract idea ( $\mathrm{T}$ 1.2.3.4-6 SBN 34). Hume says that the idea of time is "deriv'd from the succession of our perceptions of every kind" (T 1.2.3.6 SBN 34). ${ }^{31}$ His referring to "perceptions of every kind" indicates that the impressions he is thinking of come from any of the five senses. When describing how we get the idea of time, Hume says, "As 'tis from the disposition of visible and tangible objects we receive the idea of space, so from the succession of ideas and impressions we form the idea of time" (T 1.2.3.7 SBN 35). Hume sometimes refers to the succession of objects as giving us the idea of time. For example, he says time "is always discover'd by some perceivable succession of changeable objects" (T 1.2.3.7 SBN 35). The explanation is that Hume uses 'object' in two senses in the Treatise. Besides the everyday sense of physical object, Hume also uses the term in the sense of an impression that is the focus of our attention ( $\mathrm{T}$ 1.4.2.31 SBN 201). That is to say that Hume does not always use 'object' to refer to material substance. Sometimes he means an impression. For example, in T 1 2.3.7 SBN 35, the objects Hume refers to are impressions, not material substances.

Take the following example of how this reading can be applied to Hume. He argues that we perceive extension, so we must perceive its parts, and those parts are indivisible (T 1.2.3.1216 SBN 38-39). Hume then states "The same reasoning will prove, that the indivisible moments of time must be fill'd with some real object or existence, whose succession forms the duration, 
and makes it be conceivable by the mind" (T 1.2.3.17 SBN 39). Hume stipulates that "duration consists of different parts" and that "these parts are not co-existent" (T 1.2.3.8 SBN 35).

Hume says it is not "possible for time alone ever to make its appearance, or be taken notice of by the mind" ( $\mathrm{T}$ 1.2.3.7 SBN 35). If there is no succession of impressions in someone's mind, then one will be "insensible of time" (T 1.2.3.7 SBN 35). This happens when one is "in a sound sleep" or when one is "strongly occupy'd with one thought" (T 1.2.3.7 SBN 35). The rate of the succession of ideas determines the appearance of the length of the temporal duration in one's imagination ( $\mathrm{T}$ 1.2.3.7 SBN 35).

These points raise the question of whether Hume is talking about time or merely our idea of it. How, for example, can we talk of a greater or smaller rate of succession when rate requires time to be understood? It seems that for any succession to be more or less rapid, it must be more or less rapid than some other succession. Also, Hume says "Wherever we have no successive perceptions, we have no notion of time, even tho' there be a real succession in the objects" (T 1.2.3.7 SBN 35). If there can be a real succession of objects that we do not perceive, then Hume is plainly distinguishing between one person's idea of time (derived from the succession of our impressions) and time apart from one person's idea of it (derived from the succession of objects themselves).

Donald L. M. Baxter argues that, on Hume's theory, the moments that form a succession in one place coexist with other successions of other moments in a different place. ${ }^{32}$ In this way, one person's moment while deep in thought could coexist with another person's multiple moments while not deep in thought. As Baxter explains how an unchanging perception can take up time: "Hume must be implicitly allowing for a second way of taking up time in addition to having duration. ... For Hume there are two ways to take up time: (1) the way a succession does, 
or (2) the way a non-succession does. Only something taking up time the first way, has duration (in Hume's technical sense of the term)." ${ }^{33}$ According to Baxter's interpretation of Hume, a nonsuccession can occupy an interval without having duration because duration is defined as a succession. ${ }^{34}$ Hume seems to suggest in $\mathrm{T}$ 1.2.3.11 SBN 37 that an unchanging object would not produce a succession of impressions in us.

Whatever difficulties this view leads to, we must conclude from it that time cannot be single, unchanging, or unified. It cannot be single because one person may have a succession while another person does not. It cannot be unchanging because the rate of succession could speed up or slow down. It cannot be unified because the succession may cease or be interrupted. For example, on Hume's view I have no idea of time between the time that I fall asleep and the time that I awake for the simple reason that I have no succession of impressions. Yesterday and today do not form a unified time but rather form two separate times.

Additionally, Kant's claim that "all appearances are in time" (CPR A182/B224) is not one that Hume could have accepted. For Hume, it would make no sense to say that all impressions are in time, since time is abstracted from the succession of impressions. So Hume could not accept (1) from Kant's argument in the First Analogy.

Hume says that we perceive a succession of impressions (T 1.2.3.6 SBN 34), so he would have no problem with accepting (2). It is true that Hume does not mean the same thing by 'impression' that Kant does by 'appearance,' but I do not think that is significant in this context.

Hume accepts (3). Indeed, (3) is a premise of Hume's argument that we do not have the idea of identity. For example, Hume argues that "philosophy informs us, that every thing, which appears to the mind, is nothing but perception, and is interrupted, and dependent on the mind; whereas the vulgar confound perceptions and objects, and attribute a distinct continu'd existence 
to the very things they feel or see. This sentiment, then, ... is entirely unreasonable..." (T

\subsubsection{SBN 193).}

At first, it seems that Hume would have had no problem with (a), since it seems to follow from two propositions that he accepts. First, Hume holds that we have a succession of impressions. Second, Hume holds that we derive our idea of time from this succession of impressions. It follows from these two propositions that we perform time determinations. However, Kant understood time determination differently. Kant is not referring to temporal inferences about appearances, but rather he is referring to temporal inferences about objects as distinct from appearances. If this is how (a) is understood, then Hume would have rejected it.

If we understand time determination in terms of impressions, Hume would have accepted (b). That is to say, he would have affirmed (b)(i) and denied (b)(ii), which also amounts to denying (c). If we understand time determination in terms of objects, Hume would have denied (a) and (b) but affirmed (c).

Since Hume would reject (1) and at least one of (a-c) on either understanding of the words 'time determination,' he would not agree that (4) followed from the conjunction of (1-3) and (a-c). Hume could accept (4) as true in its own right if he had viewed it as a disjunction whose first disjunct is true. But he certainly would reject the second disjunct which holds that something remains or endures of which all change and coexistence is a determination. Hume would not accept (5) as an inference from (1-4) because he would not have accepted (1) or all of (a-c). Hume might accept (6) as a definition of the term 'substance,' but he denies that we have the idea of substance (T 1.4.5.6 SBN 234). So Hume would have rejected (6) as a meaningful statement. 


\section{Conclusion}

Any apparent similarity between Kant's argument in the First Analogy and various statements of Hume's is insignificant when compared to their disagreements about experience and time. Kant assumes too much of what he has already argued for previously in the Critique for the First Analogy to be a sufficient response to Hume's skepticism about objects.

Despite this, it is worth emphasizing that Kant's and Hume's views of the nature of objects are not as different as they might sometimes seem. For example, both view objects as perceptions or collections of perceptions. Hume says that objects or substances are collections of ideas: "The idea of a substance as well as that of a mode, is nothing but a collection of simple ideas, that are united by the imagination" (1.1.6.2 SBN 16, emphasis added). For Kant, "what we call outer objects are nothing other than mere representations of our sensibility" (A20/B45, emphasis added). He repeats this view in the Prolegomena: "The sensible world is nothing other than a series of appearances connected according to universal laws" (P 4:354, emphasis added). However, Kant concludes that we know that objects really exist and that Hume concludes that we do not know this. But their view of what the objects are or would be is similar.

According to Hume, substance is a fiction which we mistakenly believe in as result of our confounding a succession of similar impressions with substance (T 1.4.2.34 SBN 203). Hume argues that there can be no substance because neither unchanging nor changing content of our perceptions would justify belief in substance (T 1.4.2.26-28 SBN 200). So, as it turns out, we have no experience of substance. Therefore, we can have no idea of it.

As we have seen, Kant argues there must be substance because otherwise we could perform no time determination (CPR A182-184/B224-227). Further, Kant also argues that our 
experience is necessarily of an object (CPR B165-166). So, for Kant, the concept of an object is necessarily one we are justified in employing, since our consciousness and time-determination requires them.

So Hume and Kant's disagreement as to what experience and time are lead to different conclusions about whether we can know that there are substances.

\section{References}

Allison, Henry. Kant's Transcendental Idealism. Revised edition. New Haven: Yale University Press, 2004.

Baxter, Donald L. M. “A Defense of Hume on Identity through Time.” Hume Studies 13 (1987): $323-342$.

Baxter, Donald L. M. Hume’s Difficulty. New York: Routledge, 2008.

Beck, Lewis White. "Did the Sage of Königsberg Have No Dreams?” In Essays on Kant and Hume, 38-60. New Haven: Yale University Press, 1978.

Bennett, Jonathan. Kant's Analytic. Cambridge: Cambridge University Press, 1966.

Bird, Graham. The Revolutionary Kant. Chicago: Open Court, 2006.

Dryer, D. P. Kant's Solution for Verification in Metaphysics. Toronto: University of Toronto Press, 1966.

Falkenstein, Lorne. Kant's Intuitionism. Toronto: University of Toronto Press, 1995.

Guyer, Paul. Kant and the Claims of Knowledge. Cambridge: Cambridge University Press, 1987. Hume, David. A Treatise of Human Nature. New York: Oxford University Press, 2004.

Kant, Immanuel. Prolegomena zu einer jeden künftigen Metaphysik, die als Wissenschaft wird 
auftreten können. Köln: Könneman, 1995.

Kant, Immanuel. Kritik der reinen Vernunft. Hamburg: Felix Meiner Verlag, 1998.

Kant, Immanuel. Gesammelte Schriften: Akademie-Ausgabe. 23 vols. Charlottesville:

InteLex Corporation, 1999.

McTaggart, John M. E. The Nature of Existence, vol. 2. Cambridge: Cambridge University

Press, 1927.

Melnik, Arthur. Kant's Analogies of Experience. Chicago: University of Chicago Press, 1973.

Paton, H. J. Kant's Metaphysic of Experience, vol. 2. London: George Allen \& Unwin, 1936.

Rosenberg, Jay. "Identity and Substance in Hume and Kant.” Topoi 19 (2000): 137-145.

Strawson, P. F. The Bounds of Sense. London: Routledge, 1966.

Notes

${ }^{1}$ But see Lorne Falkenstein, Kant's Intuitionism (Toronto: University of Toronto Press, 1995), 330.

${ }^{2}$ E.g. Jay Rosenberg, "Identity and Substance in Hume and Kant," Topoi 19 (2000): 137-145. Rosenberg does not consider whether Hume would have thought Kant's argument in the First Analogy to be sound.

${ }^{3}$ I will assume throughout this paper that what Hume calls 'impressions' are the same things that Kant calls 'intuitions.' Strictly speaking, they are not the same. But the meaning of the two terms is close enough for the purposes of comparing Hume's and Kant's arguments.

${ }^{4}$ Cf. CPR A177/B220.

${ }^{5}$ See also CPR B75.

${ }^{6} \mathrm{Cf}$. Hume's arguments that we do not have the idea of personal identity (T 1.4.6 SBN 189).

${ }^{7}$ Cf. CPR A120.

${ }^{8} \mathrm{~T}$ 1.2.3.16 SBN 39, 1.3.8.10 SBN 102, 1.3.8.15 SBN 105, 1.3.14.10 SBN 160, 1.3.16.2 SBN 176, passim.

${ }^{9} \mathrm{~T}$ Intro. 4-7 SBN xv-xvi.

${ }^{10}$ See CPR B68-69, 145-146. Cf. JL 9:65 regarding how animal perception falls short of cognition: "Animals are also acquainted with [kennen] objects but do not cognize [erkennen] them."

${ }^{11}$ Lewis White Beck, "Did the Sage of Königsberg Have No Dreams?" in his Essays on Kant and Hume (New Haven: Yale University Press, 1978), 38-60.

${ }^{12}$ P. F. Strawson, The Bounds of Sense (London: Routledge, 1966), 122-123.

${ }^{13}$ H. J. Paton, Kant's Metaphysic of Experience, vol. 2 (London: George Allen \& Unwin, 1936), 199-200. But, as Paton notes at 2:200, note 2, Kant claims in the Refutation of Idealism that "only space determines in an enduring way while time, and therefore everything that is in inner sense, constantly flows" (CPR B291). That is, Kant is suggesting that time is not unchanging or unified.

${ }^{14}$ CPR Bxli, note.

${ }^{15}$ Kant repeats (5) in the Refutation of Idealism (CPR B275; see also CPR B277-278) and in the General Remark on the System of Principles (CPR B292).

${ }^{16}$ Paul Guyer, Kant and the Claims of Knowledge (Cambridge: Cambridge University Press, 1987), 216-220.

${ }^{17}$ Ibid., 219. 
${ }^{18}$ Graham Bird, The Revolutionary Kant (Chicago: Open Court, 2006), 447-448.

${ }^{19}$ Paton hints that no argument has been made for it. Paton, Kant's Metaphysic of Experience, 2:197, 201-202, 204. But see 2:199.

${ }^{20}$ D. P. Dryer, Kant's Solution for Verification in Metaphysics (Toronto: University of Toronto Press, 1966), 353354. Arthur Melnik, Kant's Analogies of Experience (Chicago: University of Chicago Press, 1973), 61-64. I will not discuss the peculiarity of Melnik's interpretation of the First Analogy as regarding determinations of "time magnitude."

${ }^{21}$ Henry Allison, Kant's Transcendental Idealism, rev. ed. (New Haven: Yale University Press, 2004), 239. Emphasis added.

${ }^{22}$ Guyer, Kant and the Claims, 216-217.

23 "The [First] Analogy takes for granted that we have to do with objective states of affairs," Bennett, Kant's Analytic, 187.

${ }^{24}$ Ibid., 201.

${ }^{25}$ Guyer, Kant and the Claims, 219-221.

${ }^{26}$ Ibid., 219-220.

${ }^{27}$ Cf. CPR A31/B46.

${ }^{28}$ Falkenstein says: "Kant should not be begging this important question [as to whether time is derived from sensations] at this stage." Kant's Intuitionism, 160.

${ }^{29}$ Ibid., 147

${ }^{30}$ Ibid., $147-148$.

${ }^{31}$ Cf. T 1.4.2.29 SBN 200.

${ }^{32}$ Donald L. M. Baxter, Hume's Difficulty (New York: Routledge, 2008), 36-37.

${ }^{33}$ Baxter, "A Defense of Hume on Identity through Time," Hume Studies 13(2) (Nov. 1987): 333.

${ }^{34}$ Ibid., 331. Baxter cites T 1.2.3.11 SBN 37 in favor of this claim. There Hume says "the idea of duration is always deriv'd from a succession of changeable objects." 